\title{
M9 Tohoku Earthquake Hydro- and Seismic Response in the Caucasus and North Turkey
}

\author{
Tamaz L. CHELIDZE ${ }^{1}$, Ia SHENGELIA ${ }^{2}$, Natalya ZHUKOVA ${ }^{1}$, \\ Teimuraz MATCHARASHVILI ${ }^{1,2}$, George MELIKADZE ${ }^{1}$, \\ and Genady KOBZEV ${ }^{1}$ \\ ${ }^{1}$ M. Nodia Institute of Geophysics, Javakhishvili Tbilisi State University, \\ Tbilisi, Georgia; e-mail: tamaz.chelidze@gmail.com \\ ${ }^{2}$ Ilia State University, Tbilisi, Georgia
}

\begin{abstract}
Presently, there are a lot of observations on the significant impact of strong remote earthquakes on underground water and local seismicity. Teleseismic wave trains of strong earthquakes give rise to several hydraulic effects in boreholes, namely permanent water level changes and water level oscillations, which closely mimic the seismograms (hydroseismograms). Clear identical anomalies in the deep borehole water levels have been observed on a large part of the territory of Georgia during passing of the $S$ and Love-Rayleigh teleseismic waves (including also multiple surface Rayleigh waves) of the 2011 Tohoku M9 earthquake. The analysis carried out in order to find dynamically triggered events (non-volcanic tremors) of the Tohoku earthquake by the accepted methodology has not revealed a clear tremor signature in the test area: the Caucasus and North Turkey. The possible mechanisms of some seismic signals of unknown origin observed during passage of teleseismic waves of Tohoku earthquake are discussed.
\end{abstract}

Key words: Tohoku earthquake, Caucasus, hydroseismic response, teleseismic waves, multiple Rayleigh waves, local seismic response.

Ownership: Institute of Geophysics, Polish Academy of Sciences;

(C) 2016 Chelidze et al. This is an open access article distributed under the Creative Commons Attribution-NonCommercial-NoDerivs license,

http://creativecommons.org/licenses/by-nc-nd/3.0/. 


\section{INTRODUCTION}

Teleseismic wave trains give rise to some hydraulic effects in boreholes, namely permanent water level ( $W L$ ) changes and water level oscillations; the former ones closely mimic seismograms and are referred as hydroseismograms (Brodsky et al. 2003, Costain and Bollinger 2010, Wang and Manga 2010, Zhang and Huang 2011). On the other hand, there are a lot of observations on the significant dynamic impact of teleseismic wave trains from strong remote earthquakes on triggering local seismicity. Remote triggering of earthquakes can be revealed by statistical analysis, namely by comparing a (local) background seismic (microseismic) events' rate with the rate in some relatively short time window after strong remote earthquake (EQ), using, e.g., Matthews and Reasenberg's approach (Matthews and Reasenberg 1988, Peng et al. 2010). A special form of the triggered events, the so called deep nonvolcanic or dynamical triggered tremors (DDTT), was revealed last years. There are several criteria that allow to identify the local seismic response as a dynamically triggered tremor: (i) the wave trains of triggered tremor bursts should be correlated with the surface wave cycle, (ii) the coherent triggered tremors should be spatially restricted to approximately $100 \mathrm{~km}$, and (iii) DDT are as a rule recorded only by stations surrounding a constrained tremor source (Hill and Prejean 2009, Prejean and Hill 2009, Gonzalez-Huizar et al. 2012, Hill et al. 2013, Parsons et al. 2014, Chao et al. 2012, 2013).

Both effects, seismohydraulic and dynamically triggered tremors, seem to be closely related to each other as one of main factors reducing local strength of rocks is the pore pressure of fluids: this is the scope of relatively new direction, called hydroseismology (Brodsky et al. 2003, Costain and Bollinger 2010, Wang and Manga 2010, Zhang and Huang 2011). At the same time as we will show later on, the strong seismohydraulic response is not a sufficient condition for generation of dynamical tremors.

Deep dynamically triggered tremors or DDTT (Hill and Prejean 2009, Prejean and Hill 2009) can be related to the fluid pore pressure change due to passage of wave trains from remote strong earthquakes; that is why we carried out integrated analysis of seismic and water level $(W L)$ data (Brodsky et al. 2003). The stresses imparted by teleseismic wave trains according to assessments are $10^{5}$ times smaller than confining stresses at the depth, where the tremors are generated. Our laboratory data on stick-slip confirm the reality of triggering and synchronization under weak mechanical forcing (Chelidze et al. 2010, Chelidze and Matcharashvili 2013, 2015). Many of the above results are still subject of intense scientific discussions due to the weakness of wave trains from remote earthquakes, but nevertheless they are quite logical in the light of undisputable strong nonlinearity of processes un- 
derlying seismicity: the tremors can be generated due to a nonlinear effect of super-sensitivity of fault system to a weak impact.

\section{MATERIALS AND METHODS}

In the paper the water level monitoring data in deep wells' network in Georgia, operated by the M. Nodia Institute of Geophysics (Fig. 1), are used. WL monitoring network in Georgia includes the following deep wells: Kobuleti, Borjomi, Akhalkalaki, Marneuli, Lagodekhi, Ajameti, and Oni (Table 1, Fig. 1). The sampling rate at all these wells is $1 / \mathrm{min}$ (except of Oni, where the sampling rate is $1 / 10 \mathrm{~min}$ ). Measurements are done by sensors MPX5010 with resolution of $1 \%$ of the scale (Freescale Semiconductors Co.; http://www.freescale.com) and recorded by datalogger XR5 SE-M (Pace Scientific Co.; http://www.pace-sci.com/data-loggers-xr5.htm) remotely by modem Siemens MC-35i Terminal (Siemens Co.) using program LogXR; data-
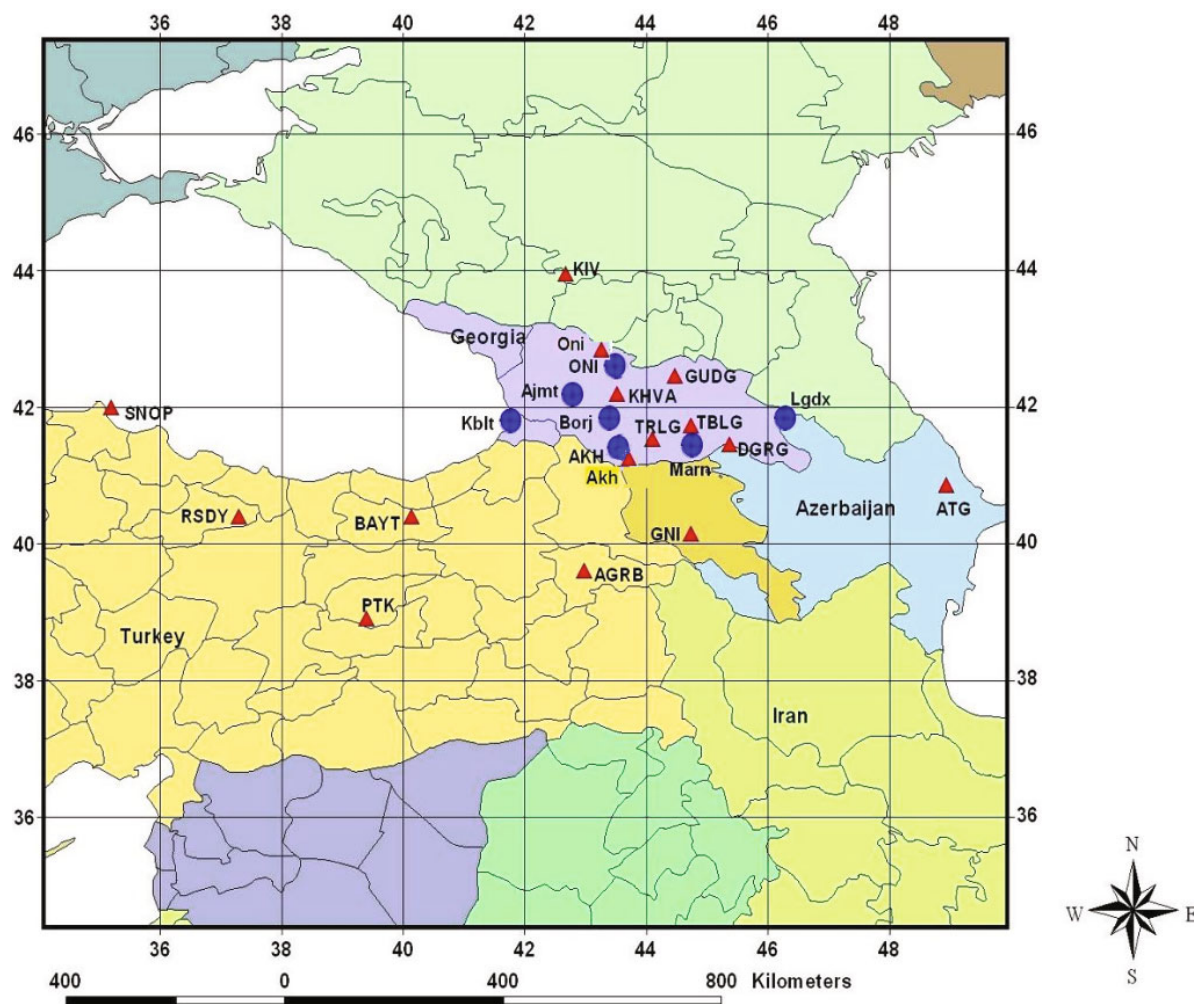

Fig. 1. Location of seismic stations (red triangles with station name abbreviations in capital letters) and deep boreholes (large blue points with regular writing), where the records of Tohoku event were analyzed. 
Locations and depths of wells in Georgia

\begin{tabular}{|l|l|c|c|l|}
\hline Location & $\begin{array}{c}\text { Name on } \\
\text { the map }\end{array}$ & $\begin{array}{c}\text { Depth } \\
\text { of well } \\
{[\mathrm{m}]}\end{array}$ & $\begin{array}{c}\text { Interval } \\
\text { of screen } \\
{[\mathrm{m}]}\end{array}$ & Aquifers' type and lythology \\
\hline Kobuleti & Kblt & 2000 & $187-640$ & $\begin{array}{l}\text { Confined sub-artesian aquifer; } \\
\text { fractured andesite-basalts }\end{array}$ \\
\hline Marneuli & Marn & 3505 & $1235-1600$ & $\begin{array}{l}\text { Confined sub-artesian aquifer; } \\
\text { fractured mergels }\end{array}$ \\
\hline Borjomi 70 & Borj & 1339 & $1260-1300$ & $\begin{array}{l}\text { Confined sub-artesian aquifer; } \\
\text { fractured limestones }\end{array}$ \\
\hline Borjomi Park & BorjP & 30 & $20-50$ & $\begin{array}{l}\text { Confined sub-artesian aquifer; } \\
\text { fractured limestones }\end{array}$ \\
\hline Akhalkalaki & Akh & 1400 & $100-1400$ & $\begin{array}{l}\text { Confined sub-artesian aquifer; } \\
\text { fractured andesite-basalts }\end{array}$ \\
\hline Ajameti & Ajmt & 1339 & $520-740$ & $\begin{array}{l}\text { Confined sub-artesian aquifer; } \\
\text { fractured limestones }\end{array}$ \\
\hline Lagodekhi & Lgdx & 800 & $255-367$ & $\begin{array}{l}\text { Confined sub-artesian aquifer; } \\
\text { fractured shales }\end{array}$ \\
\hline Oni & Oni & 255 & $70-250$ & $\begin{array}{l}\text { Confined sub-artesian aquifer; } \\
\text { fractured shale and basalts }\end{array}$ \\
\hline
\end{tabular}

logger can acquire $W L$ data for 30 days at the $1 /$ min sampling rate. Figure 1 shows also the locations of broadband seismic stations $(\mathrm{s} / \mathrm{s})$ in the Caucasus and Turkey, where the main search for local seismic effects was done.

Seismograms used in this study were downloaded from http://ds.iris.edu/ wilber3/find_event (last modified: 26 August 2014, 20:54:21 UTC). The records were bandpassed by the filter in the range of $2-10 \mathrm{~Hz}$ to reveal possible dynamically triggered events (Prejean and Hill 2009, Chao et al. 2012, 2013). For identification of possible DDTT we used the criteria, mentioned in Introduction, namely the temporal coherency of seismic signals in filtered records with the teleseismic surface waves' phases and spatial clustering of correlated local seismic signals.

\section{RESULTS AND DISCUSSION}

\subsection{Hydro-seismic effects in Georgia related to Tohoku M9 EQ}

Let us first consider anomalies in water levels $(W L)$ in deep wells' network in Georgia (Fig. 1). Regular monitoring by this network is going on for several decades. 
It was important to find $W L$ anomalous changes and compare them with teleseismic waves' phases as well as to assess pressure and stress changes of correlated seismic and $W L$ signals.

Generally (Wang et al. 2009, Zhang and Huang 2011, Wang and Manga 2010), the $W L$ response to the EQ wave trains' impact depends on the distance of the well to the ruptured fault: (i) very close to the fault, intensive shaking may increase the opening of fractures, i.e., it causes rock dilatation and, consequently, the WL dropdown; (ii) outside this zone, but still very close to the fault, shaking can consolidate loose sediments causing sudden upraise of $W L$; (iii) in the intermediate field both positive and negative signs of sustained $W L$ change are observed, which are explained by permeability changes; and (iv) lastly, in the far field (which is our case) mainly correlated with seismic wave oscillations of $W L$ are observed (hydroseismograms), sometimes accompanied with sustained $W L$ change. As the seismic impact is instantaneous, it is expected that pore water has no time to displace, which in turn means that the $W L$ response is undrained (Wang and Manga 2010).

Below (Figs. 2 and 3) we show water level response to a series of Japan earthquakes of 11 March 2011 with the following $p$-wave arrival times of the main shock and aftershocks: (a) M9; 05:57 UTC; (b) Mj7.4, 06:19 UTC; (c) Mj7.6, 06:26 UTC; and (d) Mj7.4, 06:36 UTC.

As the $W L$ values in different wells change in a very wide range, in order to show their reactions on the same plot, the signals from the $i$-th borehole $\left(W L_{i}\right)$ are plotted in conventional units, namely, they are shifted along the $y$ axis according to the expression: $\left(W L_{i}\right)=W L_{o}-\left[\min \left(W L_{i}\right)\right]+$ offset, where $W L_{o}$ is the observed $W L,\left[\min \left(W L_{i}\right)\right]$ is a minimum $W L$ in borehole for the year 2011 and the offset is a constant, needed to fit $W L$ curves into the same plot. For example, in Figs. 2 and 3 the value of $\left[\min \left(W L_{1}\right)\right]$ for Kobuleti is $106 \mathrm{~cm}$, the value of offset $=0$; for Borjomi $\left[\min \left(W L_{2}\right)\right]$ is $523 \mathrm{~cm}$; offset $6 \mathrm{~cm}$. Reduced water level value obtained after this manipulation is shown on vertical axes of Figs. 2 and 3.

The oscillations due to the EQ impact last from 12 to 24 hours in various wells.

The best correlation between teleseismic wave phases and pattern of strong $W L$ signals is for the main shock (Fig. 3a). The most important phases of strong aftershocks $(S, L, R)$ pass to late to cause major $W L$ signals. (Fig. 3b-d).

Clear $W L$ signals from the Tohoku events are fixed in Kobuleti, Borjomi Park, Marneuli (Figs. 1 and 2), and Oni boreholes. Some boreholes do not respond to the EQ: for example, Lagodekhi well does not record EQ oscillatory signal, though it manifests very good tidal variations. This should be explained by the natural frequency selectivity of the aquifer. 


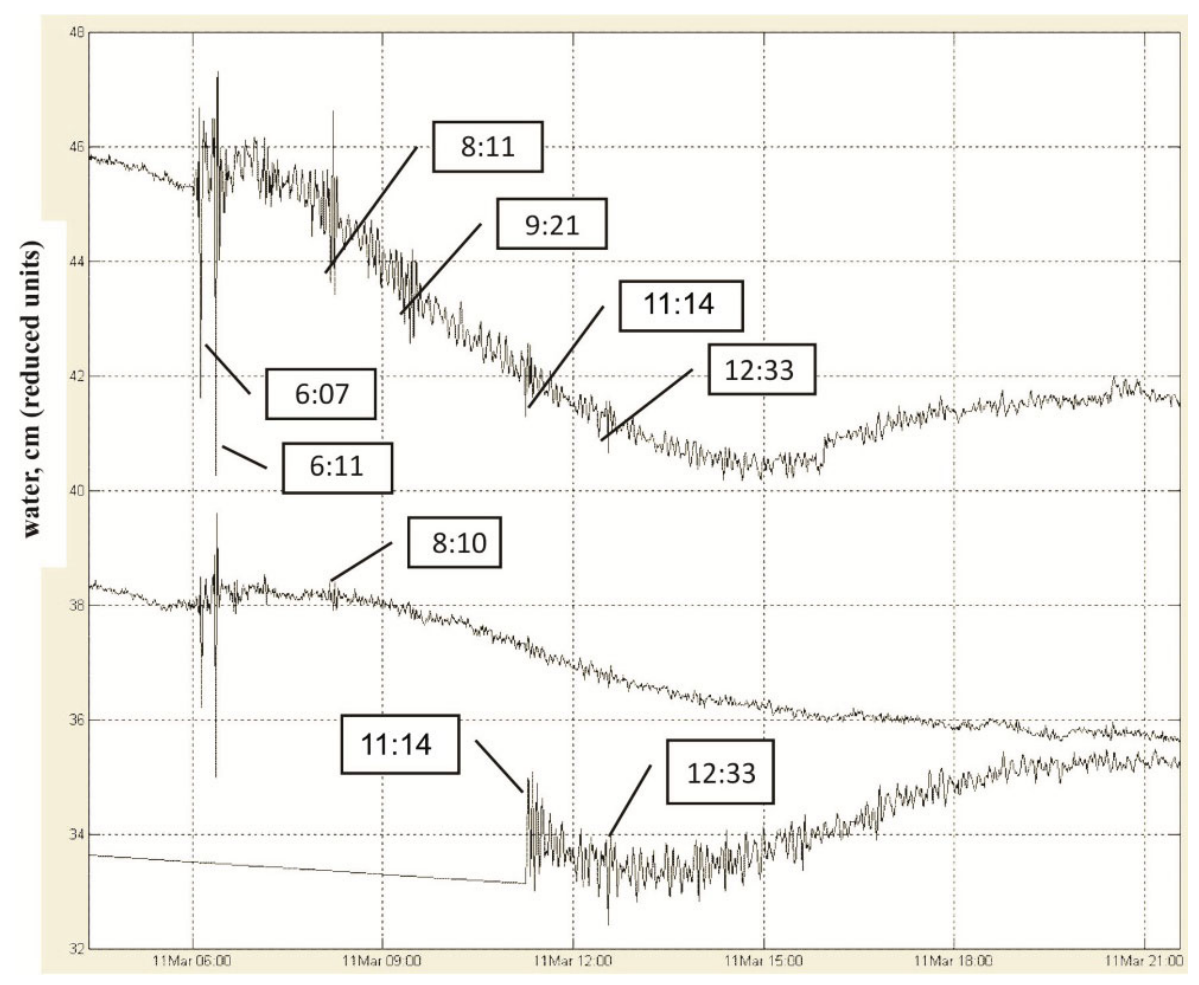

Fig. 2. Water Level change in Kobuleti (top), Borjomi Park (middle) and Marneuli (bottom) boreholes before and during the Japan M9 earthquake, 11 March 2011 in conventional units (1/min sample rate); compressed 24 hour record. Unfortunately, Marneuli data till 11:14 are lost.

Figures 2 and 3 demonstrate a striking similarity of hydraulic responses to passage of some phases of teleseismic waves from the Tohoku event in areas separated by $300 \mathrm{~km}$ : namely, to the $S$-wave and to summary impact of Love and Rayleigh waves (as the sampling rate was $1 / \mathrm{m}$, it is impossible to separate reaction to $L$ and $R$ waves). Besides phases of the main shock, the strong aftershocks of Tohoku EQ can affect $W L$ too; the first strong $\left(M_{j} 7.4\right)$ aftershock reached Tbilisi on 11 March 2011 at 06:19 UTC. Note, however, that the foreshock of Tohoku event (9 March 2011) of the same magnitude $\left(M_{j} 7.3\right)$ as well as even stronger aftershocks at 06:26 UTC (Mj7.6) and 06:36 UTC (Mj7.5) have not produced any characteristic $W L$ oscillations (not shown here).

We can conclude that there is a good coincidence between teleseismic $S$ and $L+R$ waves onsets and hydroseismic anomalies (Fig. 4). It was interesting to find, whether the wells recording oscillations due to seismic waves, re- 

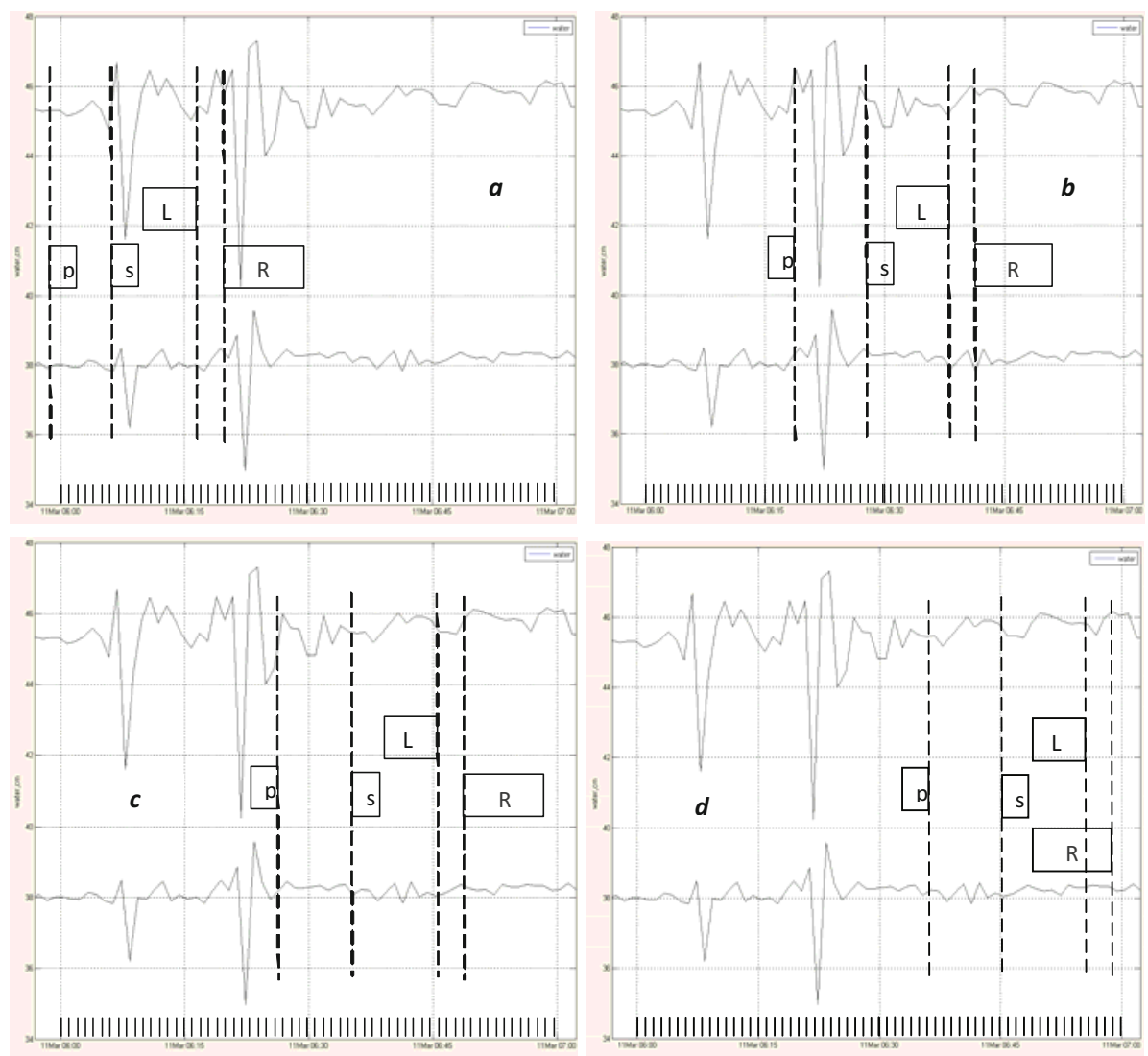

Fig. 3. Expanded records of water level change in Kobuleti (top) and Borjomi Park (bottom) at $1 / \mathrm{min}$ sampling rate before and during the first 30 minutes of Japan $M 9$ earthquake, 11 March 2011 in conventional units. Dashed lines with indexes $p, s, L$, $R$ mark arrivals of the corresponding phases generated by the main shock $M w 9$ (a), and aftershocks $M j 7.4$ (b), Mj7.6 (c), and Mj7.5, (d), respectively.

spond also to the earth tides. In Fig. 5 the two-weeks' record of $W L$ in Kobuleti well is presented: the upper figure shows the original record and the lower one - the same record after elimination of atmospheric pressure effect.

It is evident that Tohoku EQ oscillations are superimposed on the tidal variations and that both responses are of almost the same amplitude - several $(5-6) \mathrm{cm}$.

Finally, we conclude that teleseismic $S$ and $L+R$ waves of the Tohoku EQ induce significant and quite identical $W L$ anomalies on the territory of Georgia (Figs. 2-4) This means that in principle the corresponding pore pres- 


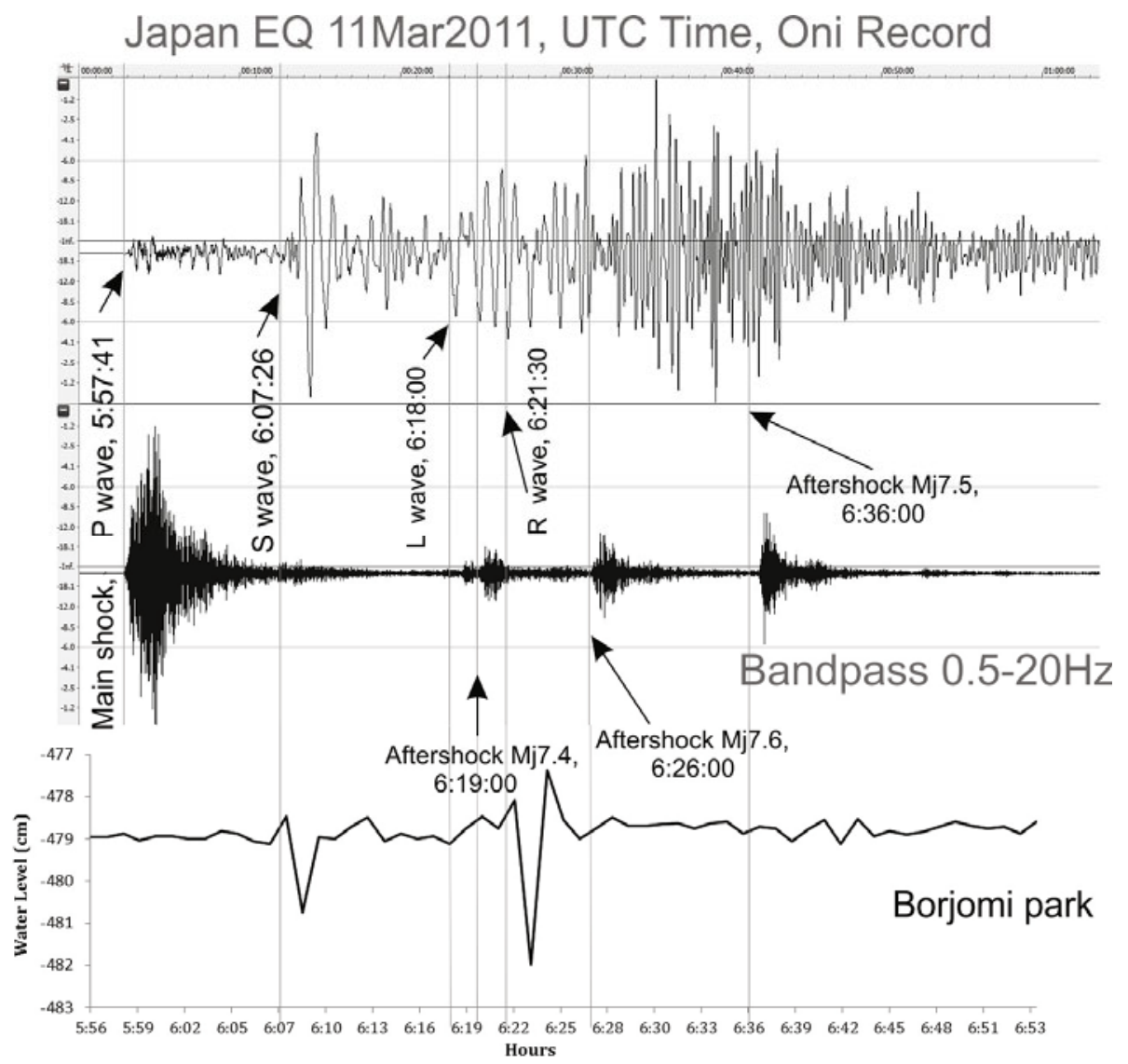

Fig. 4. The integrated plot of seismic and $W L$ events in Georgia during the Tohoku event. It is evident that the first strong $W L$ perturbation at 06:07 UTC correlates with $S$-wave offset. The second strongest $W L$ event, between 06:22 and 06:26 UTC, coincides with both the onset of $L / R$ waves' package (06:18-06:22 UTC) and the aftershock $M_{j} 7.4$ at 06:19 UTC. Note, however, that the foreshock of Tohoku event (9 March 2011) of the same magnitude $\left(M_{j} 7.3\right)$ as well as stronger aftershock $\left(M_{j} 7.5\right)$ at $06: 36$ UTC do not produce any characteristic $W L$ oscillations; thus the most probable explanation of $W L$ effect at 06:22 UTC is the passage of $L / R$ waves.

sure changes can excite some (secondary) local seismic effects, though the existing data do not allow making decisive conclusions.

\subsection{Spectrum of $W L$ oscillations following Tohoku EQ teleseismic waves}

It is evident that after the Tohoku EQ the water level undergoes characteristic oscillations, which decay in dozens of hours (Fig. 2). 


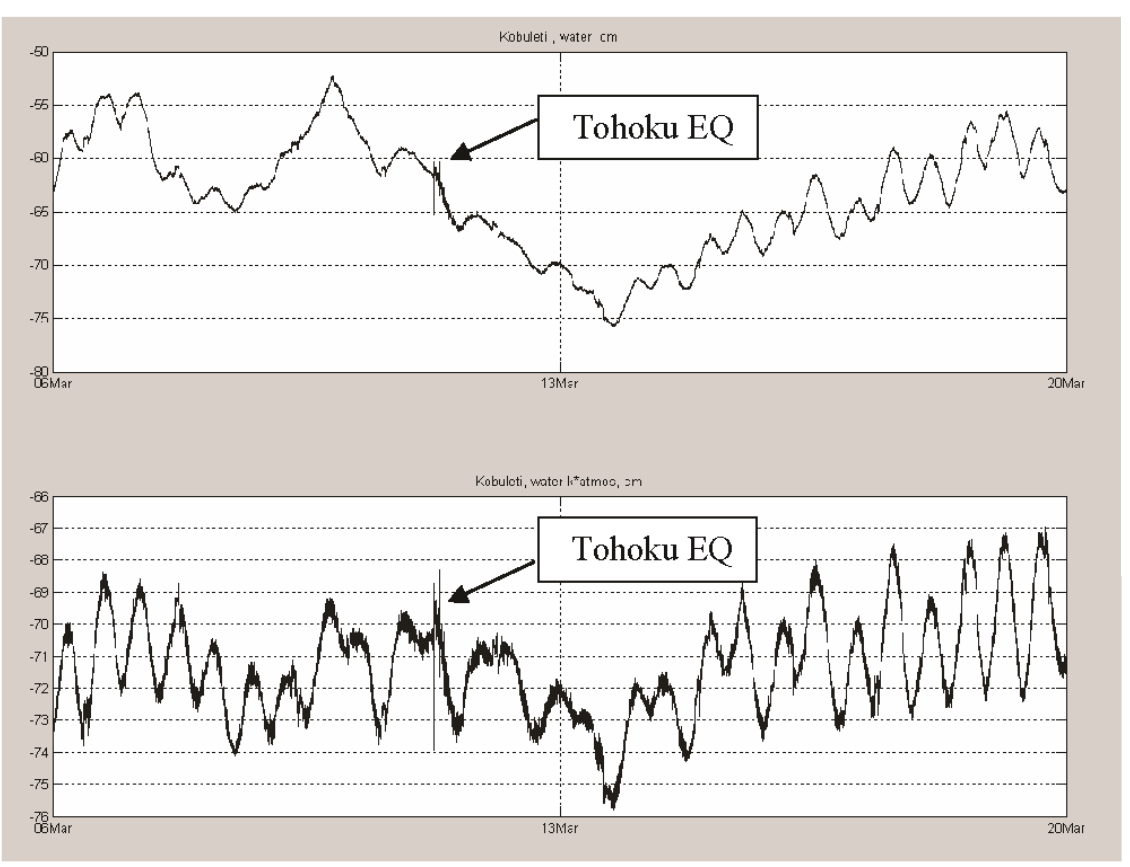

(a)

(b)

Fig. 5. WL record at Kobuleti borehole on 6-20 March 2011: (a) the original record of $W L$, absolute values, cm; (b) $W L$ after removal of atmospheric pressure effect in reduced units; note well-marked tidal variations. Arrows show the oscillations due to Tohoku EQ.

There is an interesting detail on the $W L$ plot for Kobuleti well (Fig. 2): clear delayed $W L$ perturbations are registered at the following times: 08:11, 09:21, 11:14, and 12:33 UTC, which cannot be associated with aftershocks. Some of these effects are recorded also in Borjomi and Marneuli wells (Marneuli recording is absent till 11: 14 UTC).

The spectrum and spectrogram of $W L$ oscillations for 10 and 11 March is shown in Fig. 6. After the Tohoku EQ, in the spectrum of $W L$ oscillations there appear several spikes around frequencies $2.5 \times 10^{-3} ; 4.0 \times 10^{-3} ; 4.9 \times$ $10^{-3} ; 6.2 \times 10^{-3} ; 7.2 \times 10^{-3} \mathrm{~Hz}$. The highest frequencies seem to be harmonics of the first mode $\left(2.5 \times 10^{-3} \mathrm{~Hz}\right)$ with a multiplier approximately 1.3 . The intensity of harmonics is especially high during the first 30 min after EQ. The reverberations are absent in the spectrum for 10 March (Fig. 6a, black curve). The spectrogram of the same $W L$ record also shows intensive signals around the above frequencies (Fig. 6b).

The possible explanation of these anomalies is the passage of late teleseismic phases, namely multiple surface waves circling the Earth: ac- 

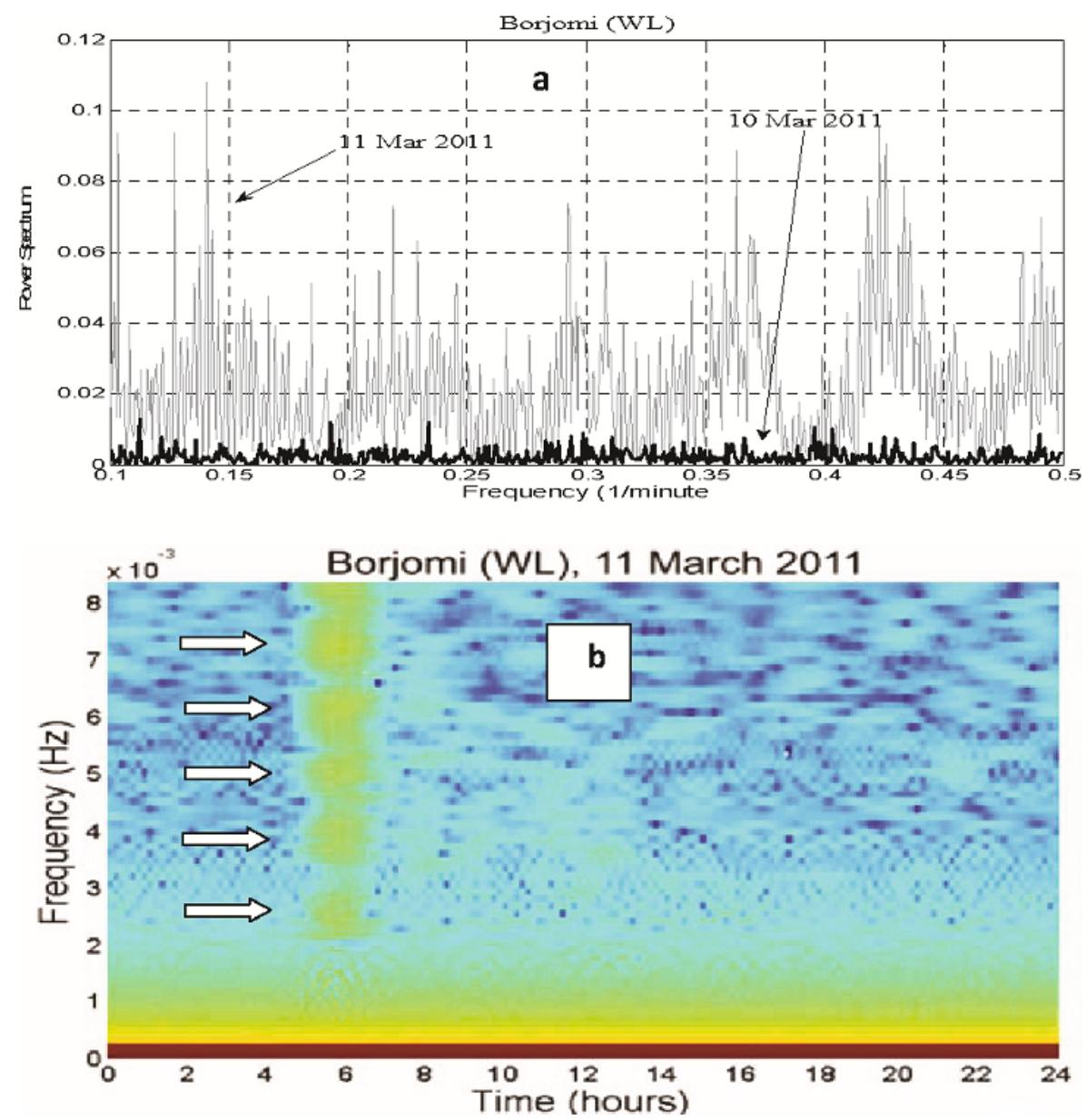

Fig. 6. Spectrum (a) and spectrogram (b) of $W L$ oscillations in Borjomi borehole before, during and after the Tohoku M9 EQ. The black curve in (a) is a background spectrum calculated for 10 March and the grey curve - for 11 March. The last one shows several strong spikes at (central) frequencies of $2.5 \times 10^{-3} ; 4.0 \times 10^{-3} ; 4.9 \times 10^{-}$ ${ }^{3} ; 6.2 \times 10^{-3} ; 7.5 \times 10^{-3} \mathrm{~Hz}$ (periods $2-7 \mathrm{~min}$ ), which are also visible in the spectrogram (b). The according spectral packages on the spectrogram are marked by arrows and probably correspond to passage of Rayleigh waves $R 1-R 5$.

cording to Peng et al. (2011) they also trigger seismic events. The observed reverberations in $W L$ hardly can be explained by the excitation of the so called Krauklis waves which propagate back and forth along fluid-filled fractures of the aquifer, emitting periodic seismic signal (Tary et al. 2014). The frequency of Krauklis wave depends on the fracture width, shear modulus of the solid, fluid density, and the ratio of shear and longitudinal 


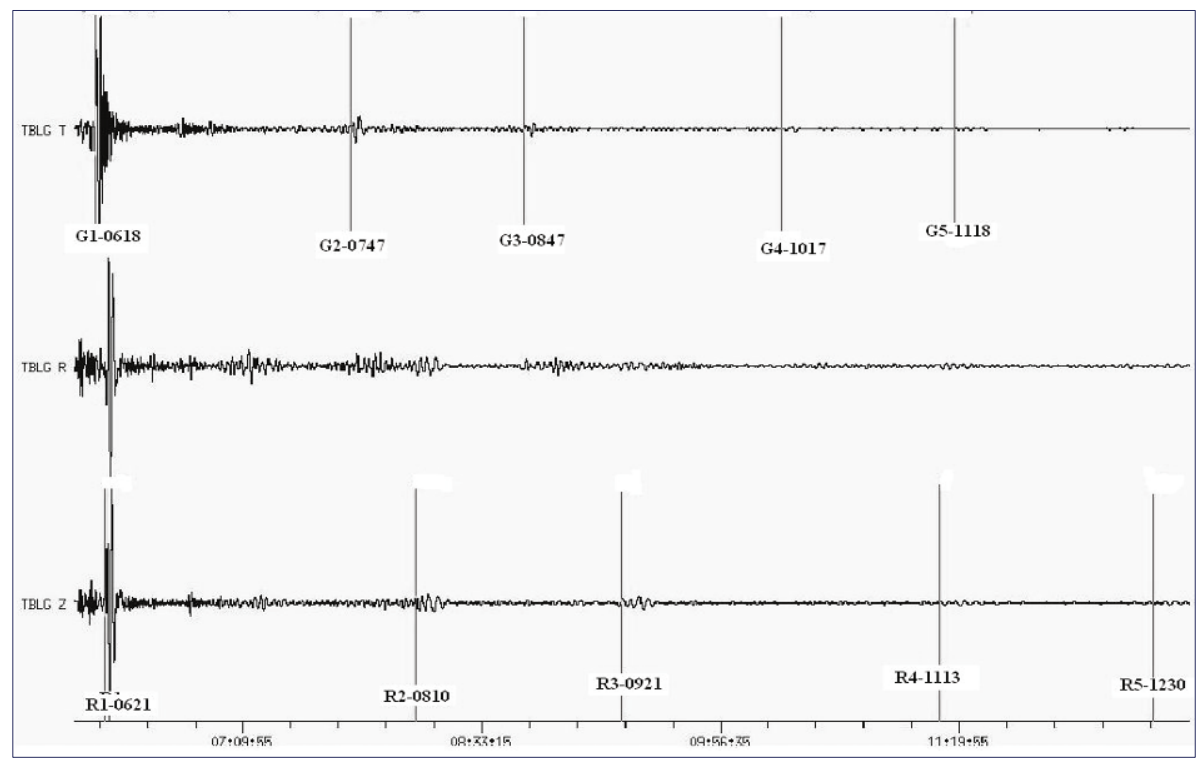

Fig. 7. Seismogram with arrivals of multiple surface $G$ and $R$ waves from the Tohoku $M 9$ EQ main shock at Tbilisi s/s.

waves and is of the order of tens of $\mathrm{Hz}$ in typical aquifers: the system should contain unrealistically long and thin cracks in order to be in the observed very low-frequency range (Fig. 6).

The most probable explanation of $W L$ oscillations with 2-7 min periods is the impact of mantle surface waves (Love and Rayleigh), which can excite seismic signals with periods up to about $500 \mathrm{~s}$ (Bormann 2012), as the $W L$ oscillations appear exactly during passage of mantle surface waves (Figs. 2 and 7). The observed $W L$ oscillations' frequencies are: $4 \times 10^{-3}$ to $R 5$; $4.9 \times 10^{-3}$ to $R 4 ; 6.2 \times 10^{-3}$ to $R 3$, and $7.5 \times 10^{-3} \mathrm{~Hz}$ to $R 2$ (Fig. 7). These $W L$ oscillation frequencies are comparable with the frequencies of mantle Rayleigh waves (Table 2). Taking into account a wide distribution of the ob-

Table 2

Comparison of periods in $W L$ oscillations with periods of multiple Rayleigh phases

\begin{tabular}{|c|c|c|}
\hline Rayleigh phases & $\begin{array}{c}\text { Periods of Rayleigh phases } \\
{[\mathrm{s}]}\end{array}$ & $\begin{array}{c}\text { Periods in } W L \text { oscillations } \\
{[\mathrm{s}]}\end{array}$ \\
\hline$R 2$ & 110 & 133 \\
$R 3$ & 155 & 161 \\
$R 4$ & 185 & 200 \\
$R 5$ & 220 & 250 \\
\hline
\end{tabular}


observed $W L$ oscillation periods (Fig. 6), the dominant $W L$ periods are close enough to these of Rayleigh phases.

We can conclude that our interpretation on coupling of $W L$ events with multiple surface $R$-wave phases is confirmed by both good coincidence of $W L$ signals and $R$-wave arrival times as well as by closeness of their frequencies' ranges.

\subsection{Study of possible local seismic response to the Tohoku earthquake in Georgia}

We speculated that the Tohoku EQ could also trigger local seismic events in Georgia and the Caucasus, which is a continental collision area, separated from Japan by $7800 \mathrm{~km}$. Though it is accepted that extensional tectonics and presence of hydrothermal sources favors dynamical triggering of local tremors (Prejean and Hill 2009), the latest analysis shows that weak "seismicity rate significantly increases immediately after ( $\sim 45 \mathrm{~min}) M 7$ mainshocks in all tectonic settings and ranges" (Parsons et al. 2014).

Figure 1 shows the location of broadband seismic stations ( $\mathrm{s} / \mathrm{s})$ in Caucasus and Turkey, where the main search for local seismic effects was done. The strongest event in the filtered signal coincides with the arrival of $p$-waves (not shown here). In the following analysis we omit mainshocks' $p$-wave effect. We used a $2-10 \mathrm{~Hz}$ bandpass filter, as the signals corresponding to $S, L$, and $R$ waves as well as signals from strong aftershocks can be distinguished in the filtered record.

Figure 8 presents the original records of Tohoku event at Tbilisi s/s (of vertical $Z$ and transverse $T$ components) as well as the $2-10 \mathrm{~Hz}$ bandpass filtered records of NS component at different seismic stations of the Caucasus, Turkey and Kiev, arranged by epicentral distance (Fig. 8 presents only a typical pattern - on the whole, more than $30 \mathrm{~s} / \mathrm{s}$ records were analyzed). Zero time on the $x$-axis is the time in the source. Note: in Fig. 8, the thin vertical lines on the original record (two upper traces) show arrivals of phases $S, S S$, $L$, and $R$ waves from the mainshock as well as $p$-wave onsets from the aftershocks, marked as A1, A2, A3, etc., with corresponding arrival times and magnitudes: A1 - 05:55 UTC, $m b=6.4$; A2 - 05:58 UTC, $m b=6.3$; A3 06:00 UTC, $m b=6.2 ;$ A4 - 06:06 UTC, $m b=6.3$; A5 - 06:07 UTC, $m b=6.4 ;$ A6 - 06:08 UTC, Mj7.4; A7 - 06:13 UTC, $m b=6.2$; A8 06:15 UTC, Mj7.6 for Tbilisi and Oni seismic stations. These stations are chosen as references for detection of teleseismic waves' phase on-sets on original record and for correlation of these onsets with some seismic signals of unknown origin (SSUO) on the filtered records. The morphology of these signals differs from strong aftershocks' $p$-wave trains. These signals have no clear onsets and manifest specific morphology, different from the strong 


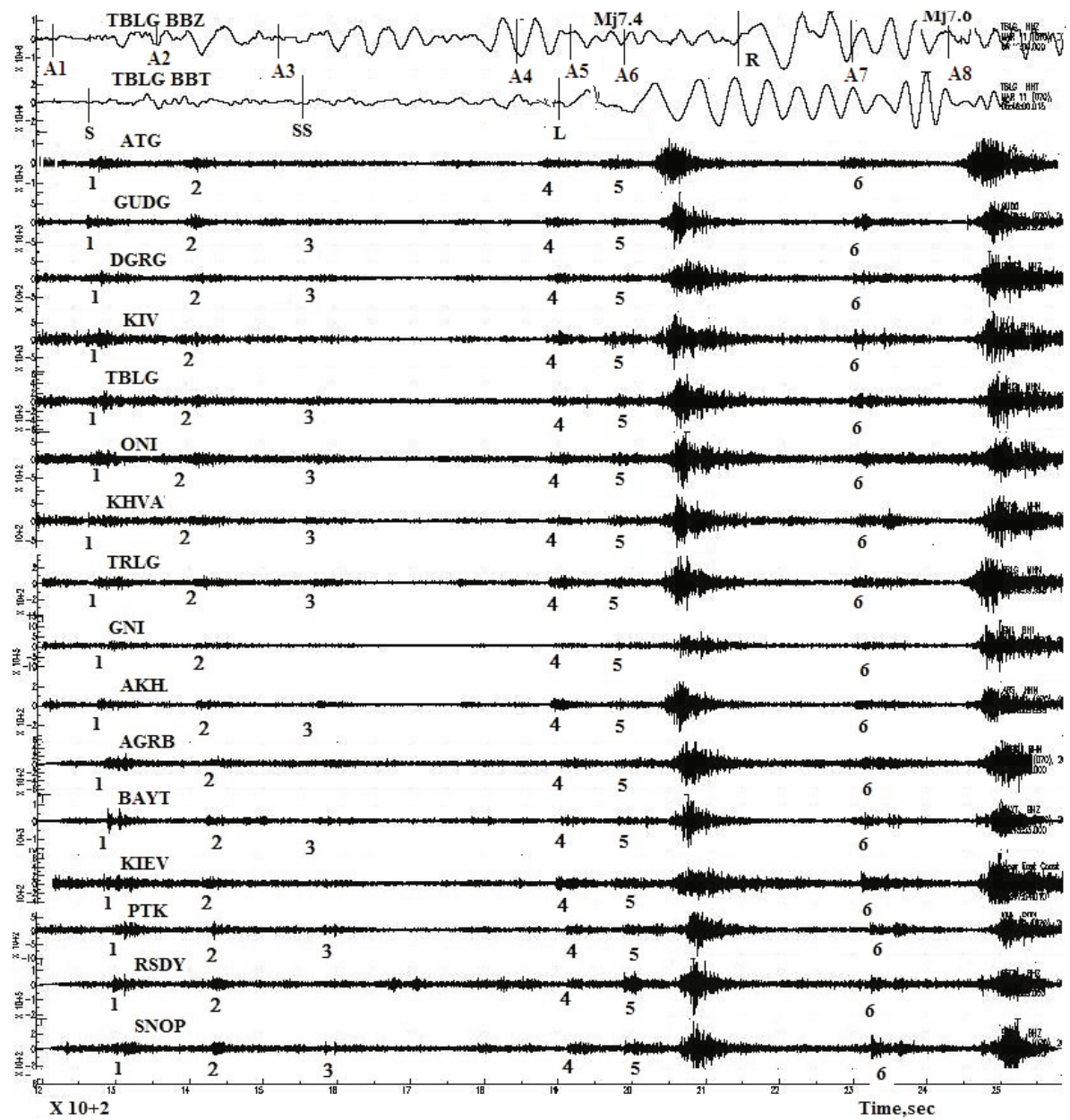

Fig. 8. Original and filtered records of Tohoku $M 9$ earthquake (11 March 2011): the upper two traces show original broadband record of vertical $Z$ and transverse $T$ components at Tbilisi seismic station. Below are shown, filtered in the bandpass 2$10 \mathrm{~Hz}$, records of NS component at the different s/s of Caucasus and Turkey arranged by epicentral distance. Zero time on the $x$-axis is the time in the source. Note: thin vertical lines on the original record (two upper traces) show onset times of phases $S, S S, L$, and $R$ waves from the mainshock and $p$-waves from the aftershocks A1, A2, A3, A4, A5, A6, A7, and A8 for Tbilisi seismic station. Numbers 1-6 mark SSUOs at different seismic stations of the region during passage of teleseismic wave trains from Tohoku EQ.

aftershocks' envelope (Fig. 8); their frequency content is defined by the bandpass used $(2-10 \mathrm{~Hz})$. The (approximate) identification of these signals was performed visually using trace-to-trace correlation principle. The num- 
bers 1 to 6 on the filtered record show successive SSUOs arrivals recorded during passage of wave trains from Tohoku EQ. We consider below some possible mechanisms of generation of these signals.

There are some details in Fig. 8 that make doubtful the existence of typical DDTT in the Caucasus. Namely, according to the existing DDTT models (Gonzalez-Huizar et al. 2012, Hill et al. 2013, Parsons et al. 2014, Peng et al. 2010, 2011, Chao et al. 2012, 2013): (i) the filtered wave trains of triggered tremors are correlated/synchronized with the $R$ or $L$ surface wave forms; (ii) the coherency of triggered tremors is spatially restricted to the area of the order of $100 \mathrm{~km}$; (iii) DDTT are recorded only by stations surrounding the constrained tremor source. The SSUOs in filtered records Fig. 8 do not follow the above model: they are not coherent with surface waves and they practically are not restricted spatially.

In what follows, we consider possible mechanisms of SSUOs arrivals 1-6 as well as their relation to the of mainshock phases and their connection with hydraulic anomalies:

- SSUOs are not of local origin and are generated by seismic energy from the Tohoku source region, namely, by mainshock/aftershocks' teleseismic phases.

- The arrival 1 can be connected with the passage of the mainshocks' $S$-wave or alternatively with the aftershock A1 of magnitude mb6.4, a signal of which arrives $45 \mathrm{~s}$ earlier than the $S$-wave offset. As even much stronger aftershocks (Mj7.6, Mj7.5) do not produce any hydraulic response, we connect the hydroseismic oscillations at the time 06:07 UTC (Figs. 3 and 5) with the $S$-wave passage.

- The arrival 2 coincides with aftershock A2 of $m b 6.3$ at 06:09 UTC or alternatively with passage of $P S, P P S, S c S$ phases, which arrived between $S$ and $S S$ waves' arrivals at the given epicentral distance: the latter version is less probable due to weakness of these phases.

a The arrival 3 can be associated with the $S S$-wave arrival as well as the A3 aftershock at 06:11 UTC of $m b 6.2$. Note that at 06:11 UTC strong hydraulic oscillations are recorded (Figs. 3and 4). Again, as even much stronger aftershocks have not produced any hydraulic response, we connect these hydroseismic oscillations at the time 06:11 UTC (Figs. 3 and 4) with the $S S$-wave passage.

Signals number 4, 5, 6 are fixed between 06:17 and 06:24 UTC. In this time interval, there arrived signals of two aftershocks, the first one - A4 at 06:17 UTC, $m b=6.3$, and the second A5 at 06:18 UTC, $m b=6.4$, as well as that of $L$-wave at 06:18 UTC. Thus, signals 4 and 5 can be related to the above aftershocks' or to $L$-wave arrival. Next, there arrived $p$-waves of A6 strong aftershock, $M j 7.4$, after which the $R$-wave arrival is registered be- 
tween 06:21 and 06:22 UTC. This is followed by the signal 6, which can be related with the aftershock $\mathrm{A} 7, m b=6.2$ and next, at $06: 26 \mathrm{UTC}$, by the $p$-wave of A8 strong aftershock, $M j 7.4$. The strong water level anomaly from 06:22 to 06:24 UTC in the deep wells on the whole territory of Georgia (see Figs. 3 and 4 ) we relate to $L-R$ waves passage (as the sample rate of $W L$ record is $1 \mathrm{~min}$ it is impossible to divide $L$ and $R$ waves impact). Taking into account the comparative impact of multiple $G-R$ waves (Figs. 3 and 4 ) the role of $R$-waves seem to be dominant in the considered $W L$ anomaly.

SSUOs are generated locally by some unconventional mechanisms. One of such mechanisms is seismic emission from a local tectonic faults, activated by the Tohoku EQ: such signals in principle can be generated by the small slips (similar to the laboratory stick-slip) along the local fault forced by passing seismic waves from Tohoku. Laboratory experiments show that very low dynamic mechanical forcing (of the order of $10^{-4}-10^{-5}$ of the main pulling force is enough to trigger stick-slip, which is synchronized with the forcing phase (Savage and Marone 2007, Chelidze et al. 2010, Chelidze and Matcharashvili 2013, 2015, Bogomolov et al. 2011, Capozza et al. 2011). This means that SSUOs can be generated by the local fault perturbation during passage of elastic wave. This hypothesis should be rejected, if SSUOs are observed in both tectonically active and stable platform areas. Analysis shows that indeed the SSUOs with the same regularities as in Fig. 8 are observed also in tectonically quiet platform regions without active faults (e.g., at Kiev s/s - Fig. 8). We conclude that the forced stick-slip hypothesis does not work.

Alternatively SSUOs can be related to the local poroelastic response of rocks to the passage of teleseismic wave trains - e.g., to generation of slow $P$-wave predicted by Biot (1962) or local fluid flow/squirt flow (Dvorkin and Nur 1993) in water containing porous rocks. According to experiments, the Biot response to seismic wave passage is too weak, so the squirt flow mechanism should be considered as a more probable one. This mechanism in principle can be ubiquitous (i.e., it can be observed anywhere along the wave path, where poroelastic response in fluid containing crustal rocks is possible) and not strictly synchronized with surface wave phase. Actually, the squirt flow mechanism (if it can be confirmed by further experiments) is close to the existing model of dynamical triggering with a difference that the local response is not spatially restricted.

The above analysis leads to conclusion that though teleseismic $S$ and $L+R$ waves of the Tohoku EQ excite significant and quite identical $W L$ anomalies on the whole territory of Georgia, which means that the corresponding pore pressure changes in principle could excite local dynamic tremors, the seismic records on the territory of Caucasus and Northern Tur- 
key do not allow making decisive conclusions related to generation of local deep, dynamically triggered tremors by this event: namely, the filtered signals 1-6 are not synchronized with $L$ - or $R$-wave phases and they are not localized in some (local) source area. The signals like 1-6 can be detected even in filtered records from Siberia to Great Britain.

So at present the mechanism of signals 1-6 seems to be most probably related to aftershocks' teleseismic waves. The absence of deep tremors can be explained: (i) by the specific tectonic position of the test area - it is considered to be a continental collision (compression) region, not favorable for dynamic tremors' triggering (Hill and Prejean 2009, Prejean and Hill 2009; Gonzalez-Huizar et al. 2012, Hill et al. 2013). Note that Pfohl et al. (2015) were also unable to reveal unambiguously the dynamically triggered tremors in the adjoining area, namely, in the Central North Anatolian Fault (CNAF), though it is in many respects similar to the San Andreas fault (SAF), where DDTTs occur persistently: namely, both CNAF and SAF are transform faults, have similar lengths, straightness, and displacements and contain fluid-rich zones. So it seems that not only the Caucasian continental collision zone, but also the transform CNAF area do not produce DDTT events; (ii) by sparseness of the seismic network in the region; (iii) by very high number of strong aftershocks after Tohoku EQ, so that many arrival times of aftershocks coincide with onsets of surface waves. This makes identification of DDTTs extremely complicated.

In the future we aim to study more general local seismic response in the presented region to several strong EQs in order to look not only for specific DDTTs, but just for remotely triggered seismicity (microseismicity) using statistical methods (see, e.g., Peng et al. 2010).

\subsection{Fusion of $W L$ and seismic effects in Georgia related to the Tohoku EQ}

In Tables 2 and 3 the seismological and $W L$ information on the Tohoku EQ impact in Georgia is presented. Here $\Delta(W L)_{m R}$ is the maximal $W L$ signal (peak-to-peak amplitude of oscillations) for $R$-group waves, cm; $\Delta P_{m R}$ is the maximal water pressure change during $R$-wave passage, $\mathrm{KPa} ; v_{S}, v_{L}$, and $v_{R}$ are, respectively, the velocity amplitudes of $S, L / G$ and $R$ waves in $\mathrm{cm} / \mathrm{s}$; $\Delta L_{S}, \Delta L_{L}$, and $\Delta L_{R}$ are, accordingly, the displacements due to $S, L / G$, and $R$ waves in $\mathrm{cm} ; \Delta \sigma_{L}$ and $\Delta \sigma_{R}$ are the dynamic stress changes for $L / G$ and $R$ waves, respectively, $\mathrm{KPa} ; \chi$ is the amplification factor of the well, calculated as the amplitude of water level oscillations in meters $\Delta(W L)_{m}$ to the particle velocity in the seismic waves $v$ (or its proxy Peak Ground Velocity PGV): $\chi=\Delta(W L)_{m} / v$ in units $\mathrm{m} /(\mathrm{m} / \mathrm{s})$ (Brodsky et al. 2003). 
Table 3

Seismic and seismohydraulic responses to Tohoku (M9) EQ in Georgia

\begin{tabular}{|l|c|c|c|c|c|c|c|c|c|c|}
\hline $\begin{array}{c}\text { Site } \\
\text { name }\end{array}$ & $\begin{array}{c}\Delta(W L)_{m R} \\
{[\mathrm{~cm}]}\end{array}$ & $\begin{array}{l}\Delta P_{m, R} \\
{[\mathrm{KPa}]}\end{array}$ & $\begin{array}{c}v_{S} \\
{[\mathrm{~cm} / \mathrm{s}]}\end{array}$ & $\begin{array}{c}\Delta L_{S} \\
{[\mathrm{~cm}]}\end{array}$ & $\begin{array}{c}v_{L} \\
{[\mathrm{~cm} / \mathrm{s}]}\end{array}$ & $\begin{array}{c}\Delta L \\
{[\mathrm{~cm}]}\end{array}$ & $\begin{array}{c}v_{R} \\
{[\mathrm{~cm} / \mathrm{s}]}\end{array}$ & $\begin{array}{c}\Delta L_{R} \\
{[\mathrm{~cm}]}\end{array}$ & $\begin{array}{c}\Delta \sigma_{L} \\
\Delta \sigma_{R} \\
{[\mathrm{KPa}]}\end{array}$ & $\begin{array}{c}X \\
{[\mathrm{~m} /(\mathrm{m} / \mathrm{s})]}\end{array}$ \\
\hline $\begin{array}{l}\text { Kobuleti } \\
\text { Borjomi } \\
\text { Park }\end{array}$ & 8 & 0.8 & 0.1 & 1 & 0.09 & 1.4 & 0.11 & 1.2 & 11 & 80 \\
Oni & 10 & 0.4 & 0.1 & 1 & 0.09 & 1.4 & 0.11 & 1.2 & 11 & 89 \\
\hline
\end{tabular}

Love/Rayleigh phases induce maximal $W L$ displacement (peak-to-peak amplitude), which vary from $4 \mathrm{~cm}$ in Borjomi to $10 \mathrm{~cm}$ in Oni. The hydraulic effect (displacement) is 4-10 times larger than seismic $L$ or $R$ wave displacement. In order to estimate dynamic stress (Chao et al. 2012, 2013) we measure the peak ground velocity for the Love and Rayleigh waves in the instrument-corrected NS and vertical component seismograms, respectively (Table 3$)$. Then we calculate the corresponding dynamic stress $(\Delta \sigma)$ based on the equation: $\Delta \sigma=G(d u / d t) / v$, where $G$ is the average shear rigidity of crust $-35 \mathrm{GPa}, v$ - phase velocities amounting to 4.0 and $3.5 \mathrm{~km} / \mathrm{s}$ for Love and Raylegh waves, respectively, and $(d u / d t)$ is a Peak Ground Velocity (PGV). Measured PGVs for Love and Rayleigh waves are 0.09 and $0.1 \mathrm{~cm} / \mathrm{s}$, respectively. So the corresponding dynamic stress is about $10 \mathrm{KPa}$. These data allow calculating the amplification factor $\chi$, which turns to be of the order of $80 \pm 10 \mathrm{~m} /(\mathrm{m} / \mathrm{s})$. Interestingly, the calculation of the similar factor for tidal response $\chi_{t}$, (Fig. 5) results very low amplification value: $\chi_{t} \approx 3.10^{-6} \mathrm{~m} /(\mathrm{m} / \mathrm{s})$ due to a low velocity of deformation.

The different $W L$ responses in different boreholes to practically the same mechanical impact $(11 \mathrm{KPa})$ is explained by the difference in aquifers' transmissivity/storage: large amplitudes of $W L$ are favored by a high transmissivity/low storativity (Wang and Manga 2010, Brodsky et al. 2003).

Generally, it was earlier accepted that the main impact on $W L$ should cause Rayleigh wave as it provokes volume change. The strong enough response of $W L$ to $S$ - and Love waves passage was considered less probable as these waves do not cause volumetric strain. Nevertheless, recent observations document $W L$ coherent oscillations with $S$ and Love waves (Wang and Manga 2010). Our data also confirm significant impact of $S$ wave on $W L$ in Georgia boreholes (Figs. 2-4).

The most effective in delayed triggering of microearthquakes are the first three groups of multiple surface waves (G1-R1, G2-R2, etc.). Indeed, analysis of seismograms shows that exactly at the above-mentioned times of $W L$ perturbations there arrive multiple surface waves $R 2$ (08:10), $R 3(09: 21), R 4$ 
Table 4

Seismic and hydraulic response to the multiple surface waves $(R 2, R 3, R 4, R 5$

and $G 2, G 3, G 4, G 5)$ of Tohoku, $M 9$, EQ in Kobuleti, Georgia

\begin{tabular}{|c|c|c|c|c|c|c|c|c|c|}
\hline $\begin{array}{c}\text { Site } \\
\text { name }\end{array}$ & $\begin{array}{c}\Delta(W L)_{m R} \\
{[\mathrm{~cm}]}\end{array}$ & $\begin{array}{c}\Delta P_{m R} \\
{[\mathrm{KPa}]}\end{array}$ & $\begin{array}{c}\Delta(W L)_{m G} \\
{[\mathrm{~cm}]}\end{array}$ & $\begin{array}{c}\Delta P_{m G} \\
{[\mathrm{KPa}]}\end{array}$ & $\begin{array}{c}v_{G} \\
{[\mathrm{~cm} / \mathrm{s}]}\end{array}$ & $\begin{array}{c}\Delta \sigma_{G} \\
{[\mathrm{KPa}]}\end{array}$ & $\begin{array}{c}v_{R} \\
{[\mathrm{~cm} / \mathrm{s}]}\end{array}$ & $\begin{array}{c}\Delta \sigma_{R} \\
{[\mathrm{KPa}]}\end{array}$ & $\left.\begin{array}{c}\chi \\
{[\mathrm{m} /(\mathrm{m} / \mathrm{s})}\end{array}\right]$ \\
\hline & 3.20 & 0.32 & - & - & $\begin{array}{l}\mathrm{G} 2- \\
0.030\end{array}$ & 3.0 & $\begin{array}{l}\mathrm{R} 2- \\
0.020\end{array}$ & 2.0 & 160 \\
$\frac{\overrightarrow{0}}{\vec{\Xi}}$ & 1.65 & 0.17 & - & - & $\begin{array}{l}\mathrm{G} 3- \\
0.015\end{array}$ & 1.5 & $\begin{array}{l}\mathrm{R} 3- \\
0.018\end{array}$ & 1.5 & 90 \\
\multirow{0}{0}{} & 1.26 & 0.13 & - & - & $\begin{array}{l}\mathrm{G} 4- \\
0.007\end{array}$ & 0.7 & $\begin{array}{l}\mathrm{R} 4- \\
0.008\end{array}$ & 0.7 & 160 \\
& 0.90 & 0.09 & - & - & $\begin{array}{l}\mathrm{G} 5- \\
0.003\end{array}$ & 0.3 & $\begin{array}{l}\mathrm{R} 5- \\
0.006\end{array}$ & 0.5 & 150 \\
\hline
\end{tabular}

(11:13), and $R 5$ (12:30), which travelled at 289, 431, 649, and 791 degrees, respectively (Bormann 2012). Thus, we show that multiple surface $R$ waves can generate not only local microseismicity (Peng et al. 2011), but also significant $W L$ signals. On the other hand $W L$ does not respond to the arrival of Love waves $(G 1, G 2$, etc. - compare Figs. 2 and 7). Thus, the $W L$ signals, recorded at $08: 11,9: 21,11: 14$, and 12:33 UTC, are definitely triggered by passing multiple surface $R$ waves.

Table 4 summarizes seismic and $W L$ responds to the multiple surface waves of the Tohoku $M 9$ event: here in addition to symbols of Table 3 the following notations are introduced: $\Delta(W L)_{m G}$ is the maximal $W L$ signal (peak-to-peak amplitude of oscillations) for $G$-group waves, cm; $\Delta P_{m G}$ is the maximal water pressure change during $G$-wave passage, $\mathrm{KPa}$; $v_{G}$ is the velocity of a given $G$ wave in $\mathrm{cm} / \mathrm{s}$. According to Table 4, the amplification factor is almost the same for all multiple $R$-waves despite big difference in $v_{R}$.

We can conclude that though the stress change imparted by multiple surface waves of both $G$ and $R$ groups are comparable (Table 4), the $W L$ responds strongly only to the $R$-waves impact. This result is in agreement with the statement that to change $W L$, the porous space should consolidate or dilate; Rayleigh waves give rise to volumetric strain which satisfies this model (Wang and Manga 2010). At the same time the recent data (Wang and Manga 2010, Hill et al. 2013, Wang et al. 2009) as well as our results show that $S$ and $S S$ waves also significantly change $W L$. The mechanisms suggested for explanation of the latter observation include anisotropic poroelastic effect (Brodsky et al. 2003), permeability enhancement of fractured rocks due to removal of blocking elements by oscillating fluid (Wang and Manga 2010) or just strong anisotropy/heterogeneity of aquifer rocks, which can add vol- 
umetric component to a shear displacement; such effect is absent in isotropic homogeneous material.

Thus our new observation obtained by integrated analysis of seismic and water level records (hydroseismograms) documents, for the first time, that multiple surface $R$ waves generate not only local microseismicity (Peng et al. 2011), but also significant synchronous $W L$ signals (unlike less efficient multiple surface $G$ waves), see Figs. 2 and 7. At present we cannot explain, why Love mantle surface waves do not excite $W L$ oscillations, though $S$ waves do - here we just fix the experimental observation.

\section{CONCLUSIONS}

The borehole network of Georgia registered clear anomalies during passage of $S$ and Love + Rayleigh teleseismic waves of the Tohoku mainshock. The strong hydraulic events with amplitude of $8-10 \mathrm{~cm}$, correlated with passage of $S$ and $L-R$ waves, are caused by mechanical displacement of the order of $1 \mathrm{~cm}$, i.e., $W L$ response to displacement is amplified 8-10 times when mechanical stress change by $11 \mathrm{KPa}$. It should be noted that the $W L$ response at wells separated by hundreds of $\mathrm{km}$ are practically identical. Besides the $W L$ response to the first arrivals of $S$ and Love-Rayleigh phases, there are some clear delayed $W L$ perturbations, which document for the first time that passage of multiple surface Rayleigh waves, $R 2, R 3, R 4$, and $R 5$, imparting dynamic stresses of the order of $0.5-2 \mathrm{KPa}$, also can affect the $W L$ regime. The amplification factor for multiple $S$ and $L+R$ waves is of the order of 80 .

Though teleseismic $S$ and $L+R$ waves of Tohoku EQ excite significant and quite identical $W L$ anomalies on the whole territory of Georgia, which means that corresponding pore pressure changes in principle could excite local dynamic tremors, the seismic records on the territory of Caucasus and North Turkey do not allow making decisive conclusions related to generation of local deep dynamically triggered tremors by this event. This can be explained by the specific tectonic position of the test area - it is considered as a continental collision (compression) region, not favorable for dynamic triggering as well as sparse seismic network and enormous number of aftershocks, which mask surface waves' onsets. The seismic signals of unknown origin detected in the region on the bypass $(2-10 \mathrm{~Hz})$ filtered records do not correspond to the accepted dynamically triggered tremors criteria and can be explained either by remote strong event source impact (Tohoku aftershocks) or, less probably, by local poroelastic response. We can conclude that at present no deep dynamically triggered tremors (DDTTs) were revealed in the Caucasus and adjoining territory of North Turkey. Recent study of Pfohl et al. (2015) lead to the same results for the Central Anatolian Fault area. 
Acknowledgments. The authors express their gratitude to the Rustaveli National Science Foundation of Georgia (Project FR/567/9-140/12) for the financial support, the Seismic Monitoring Center of Ilia State University of Georgia, National Seismic Network of Azerbaijan (Dr. T. Mammadli) and National Seismic Network System of Turkey (Dr. D. Kalafat) for rendering digital records.

\section{References}

Biot, M.A. (1962), Mechanics of deformation and acoustic propagation in porous media, J. Appl. Phys. 33, 4, 1482-1498, DOI: 10.1063/1.1728759.

Bogomolov, L.M., A.S. Zakupin, and V.N. Sichev (2011), Electrical Impacts on the Earth Crust and Variations of Weak Seismicity, Lambert Academic Publ., Saarbrücken, 408 pp (in Russian).

Bormann, P. (ed.) (2012), New manual of seismological observatory practice (NMSOP-2), IASPEI, GFZ German Research Centre for Geosciences, Potsdam, DOI: 10.2312/GFZ.NMSOP-2, http://nmsop.gfz-potsdam.de.

Brodsky, E.E., E. Roeloffs, D. Woodcock, I. Gall, and M. Manga (2003), A mechanism for sustained groundwater pressure changes induced by distant earthquakes, J. Geophys. Res. 108, B8, 2390, DOI: 10.1029/2002JB002321.

Capozza, R., S.M. Rubinstein, I. Barel, M. Urbakh, and J. Fineberg (2011), Stabilizing stick-slip friction, Phys. Rev. Lett. 107, 2, 024301; DOI: 10.1103/ PhysRevLett.107.024301.

Chao, K., Z.G. Peng, C.Q. Wu, C.C. Tang, and C.H. Lin (2012), Remote triggering of non-volcanic tremor around Taiwan, Geophys. J. Int. 188, 1, 301-324, DOI: 10.1111/j.1365-246X.2011.05261.x.

Chao, K., Z. Peng, H. Gonzalez-Huizar, C. Aiken, B. Enescu, H. Kao, A.A. Velasco, K. Obara, and T. Matsuzawa (2013), A global search for triggered tremor following the $2011 \mathrm{M}_{\mathrm{w}} 9.0$ Tohoku earthquake, Bull. Seismol. Soc. Am. 103, 2B, 1551-1571, DOI: 10.1785/0120120171.

Chelidze, T., and T. Matcharashvili (2013), Triggering and synchronization of seismicity: Laboratory and field data - a review. In: K. Konstantinou (ed.), Earthquakes - Triggers, Environmental Impact and Potential Hazards, Nova Science Pub., New York, 165-231.

Chelidze, T. and T. Matcharashvili (2015), Dynamical patterns in seismology. In: C.L. Webber Jr. and N. Marwan (eds.), Recurrence Quantification Analysis: Theory and Best Practices, Springer, Cham Heidelberg, 291-334.

Chelidze, T.,T. Matcharashvili, O. Lursmanashvili, N. Varamashvili, N. Zhukova, and E. Meparidze (2010), Triggering and synchronization of stick-slip: Experiments on spring-slider system. In: V. de Rubeis, Z. Czechowski, and R. Teisseyre (eds.), Synchronization and Triggering: from Fracture to 
Earthquake Processes, GeoPlanet: Earth and Planetary Sciences, Springer, Heidelberg, 123-164.

Costain, J.K., and G.A. Bollinger (2010), Review: Research results in Hydroseismicity from 1987 to 2009, Bull. Seismol. Soc. Am. 100, 5A, 18411858, DOI: 10.1785/0120090288.

Dvorkin, J., and A. Nur (1993), Dynamic poroelasticity: A unified model with the squirt and the Biot mechanisms, Geophysics 58, 4, 524-533, DOI: 10.1190/ 1.1443435 .

Gonzalez-Huizar, H., A.A.Velasco, Z. Peng, and R.R. Castro (2012), Remote triggered seismicity caused by the 2011, M9.0 Tohoku-Oki, Japan earthquake, Geophys. Res. Lett. 39, 10, L10302, DOI: 10.1029/2012GL051015.

Hill, D. and S. Prejean (2009), Dynamic triggering. In: H. Kanamori (ed.), Earthquake Seismology, Elsevier, Amsterdam, 257-293.

Hill, D.P., Z. Peng, D.R. Shelly, and C. Aiken (2013), S-wave triggering of tremor beneath the Parkfield, California, section of the San Andreas fault by the 2011 Tohoku, Japan, earthquake: Observations and theory, Bull. Seismol. Soc. Am. 103, 2B, 1541-1550, DOI: 10.1785/0120120114.

Matthews, M.V., and P.A. Reasenberg (1988), Statistical methods for investigating quiescence and other temporal seismicity patterns, Pure Appl. Geophys. 126, 2-4, 357-372, DOI: 10.1007/BF00879003.

Parsons, T., M. Segou, and W. Marzocchi (2014), The global aftershock zone, Tectonophysics 618, 1-34, DOI: 10.1016/j.tecto.2014.01.038.

Peng, Z., W. Wang, Q.-F. Chen, and T. Jiang (2010), Remotely triggered seismicity in north China following the $2008 \mathrm{M}_{\mathrm{w}} 7.9$ Wenchuan earthquake, Earth Planets Space 62, 11, 893-898, DOI: 10.5047/eps.2009.03.006.

Peng, Z., C. Wu, and C. Aiken (2011), Delayed triggering of microearthquakes by multiple surface waves circling the Earth, Geophys. Res. Lett. 38, 4, L04306, DOI: 10.1029/2010GL046373.

Pfohl, A., L.M. Warren, S. Sit, and M. Brudzinski (2015), Search for tectonic tremor on the Central North Anatolian fault, Turkey, Bull. Seismol. Soc. Am. 105, 3, 1779-1786, DOI: 10.1785/0120140312.

Prejean, S., and D. Hill (2009), Dynamic triggering of earthquakes. In: R.A. Meyers (ed.), Encyclopedia of Complexity and Systems Science, Springer, New York, 2600-2621.

Savage, H.M., and C. Marone (2007), Effects of shear velocity oscillations on stickslip behavior in laboratory experiments, J. Geophys. Res. 112, B2, 112B, DOI: 10.1029/2005JB004238.

Tary, J.B., M. van der Baan, and D.W. Eaton (2014), Interpretation of resonance frequencies recorded during hydraulic fracturing treatments, J. Geophys. Res. 119, 2, 1295-1315, DOI: 10.1002/2013JB010904.

Wang, C.-Y., and M. Manga (2010), Earthquakes and Water, Lecture Notes in Earth Sciences, Springer, Heidelberg, DOI: 10.1007/978-3-642-00810-8. 
Wang, C.-Y., Y. Chia, P.-L. Wang, and D. Dreger (2009), Role of S waves and Love waves in coseismic permeability enhancement, Geophys. Res. Lett. 36, 9, L09404, DOI: 10.1029/2009GL037330.

Zhang, Y., and F. Huang (2011), Mechanism of different coseismic water-level changes in wells with similar epicentral distances of intermediate field, Bull. Seismol. Soc. Am. 101, 4, 1531-1541, DOI: 10.1785/0120100104.

Received 20 May 2015

Received in revised form 21 August 2015

Accepted 1 September 2015 